\title{
Bacillus Fermentation of Soybean: A Review
}

\author{
ASHOK KUMAR SHRESTHA ${ }^{1 *}$, NAWA RAJ DAHAL ${ }^{2}$ and VEDASTE NDUNGUTSE ${ }^{1}$ \\ ${ }^{1}$ Centre for Nutrition and Food Sciences, The University of Queensland, St Lucia, Queensland 4072, \\ Brisbane, Australia \\ ${ }^{2}$ Department of Food Technology and Quality Control, Kathmandu, Nepal
}

\begin{abstract}
Soybeans in its natural form have a little direct use as a food due to its poor digestibility as well as beany taste and flavour. Fermentation; however, can improve the eating and nutritional qualities of soybeans. Fermented soybean foods have been an intricate part of oriental diet for a long time. Bacillus subtilis dominated traditionally fermented soyfoods have typical taste, texture and aroma which is popular in Asian and African countries. B. subtilis fermentation of soaked and cooked soybeans brings many physico-chemicals and sensory changes that make it highly digestible and nutritious. This paper reviews various facets of B. subtilis fermented traditional foods, properties of fermenting organisms, preparation of such fermented foods, changes in chemical composition and nutritional properties and improving the quality of these foods.
\end{abstract}

Keywords: Soyabean, Bacillus fermentation, Health benefits, Acceptability, Commercialization

\section{Introduction}

Soybean (Glycine max L.) is one of the nutritionally richest natural vegetable foods known to human kind, records of its food usage dates back to $2838 \mathrm{BC}$ in China. Although having high protein content, minerals, vitamins and bio-actives, it has little direct use because of high satiety value caused by high oil content, poor digestibility, green beany taste, long cooking time and persistent bitterness. Soybeans as a food is used as soymilk, soy flour, soy oil, feed for livestock and poultry, soy concentrate, protein isolates, soy yoghurt, tofu and fermented foods such as Tempeh, soy sauce, Miso, Natto and Sufu (Beuchat, 1984). Fermentation is a proven method to improve flavour, texture and nutritional quality of the soybeans. Besides bringing physico-chemical and sensory quality changes, fermentation contributes towards the preservation of food due to release of metabolites that discourage the growth of pathogenic bacteria in foods. Fermentation involves a range of microorganisms such as lactic acid bacteria, acetic acid bacteria, yeasts, moulds and a range of bacteria. It also covers wide range of products such as staples, adjuncts to staples, condiments and beverages that use substrates such as cereals, pulses, soybeans, flowers, milk, meat etc. (Tamang and Sarkar, 1988).

There are many traditional B. subtilis fermented soybeans foods in various parts of the world. One of the common examples is Kinema which is traditionally consumed by the non-Brahmin Nepali inhabiting Nepal; Darjeeling and Sikkim of India; and some parts of Bhutan. It is popular among Lepchas and Bhutias who call it 'Satlyangser' and 'Bari', respectively (Sarkar et al., 1994). Yoshida (1988) reported the origin of Kinema in Southern part of China. While it spread, this food settled into a niche as seasonings in East Nepal, North East India, Burma, Thailand and in Japan. Some Kinema

\footnotetext{
*Corresponding author, E-mail: a.shrestha@uq.edu.au
}

like fermented soy foods reported in literature are: 'Natto' in Japan, 'Thua-Nao' in Thailand, 'Douchi' in China, 'Chungkook-jong' in Korea, 'Tao-si' in Philippines, 'Dawadawa' in Africa (Sarkar et al., 1994; Shrestha and Noomhorm, 2001; Hu et al., 2010). With its powerful odour and slimy appearance like a rotten food, large number of population do not like it, whereas other finds eating Kinema (and similar products) a delightful experience. These foods are eaten in the fresh form or as a fried curry dish along with boiled rice and sometime with boiled rice, and sometimes as soup, pickle or mixed with other vegetables (Shrestha, 1989).

Bacillus spp. is the most dominant naturally fermenting agents in soybeans. These hydrolytic bacteria are associated with utilization and reduction of indigestible oligosaccharides and polysaccharides. The organism has also shown to reduce the activity of anti-nutrients that hinders availability of proteins and phytochemicals present in soybeans (Sarkar et al., 1997; Esteves et al. 2010). B. subtilis fermentation is accompanied by covering intact granules with white-coloured viscous substance, slimy appearance, softer texture, and unique 'rotten' flavour. It also completely removes the beany odour of raw soybeans and increases sensory quality of the product (Sarkar and Tamang, 1994; Shrestha and Noomhorm, 2001; Hu et al., 2010). The current paper will review various aspects of Bacillus fermentation of soybeans, particularly chemical changes that lead to improvement of nutritional and sensory qualities of soybeans. It will also investigate the potential benefits of Bacillus fermentation on human health, storability and other aspects as a food.

\section{Soybean fermentation and fermenting Bacilli}

Fermenting bacilli encompasses a group of bacteria with various similarities, or dissimilarities (Neway, 1989). They are mostly gram positive, aerobic, rod-shaped, heat resistant and spore forming bacteria. Bacillus can produce different variety 
of enzymes including polysaccharides, proteins and nucleic acid hydrolysing enzymes during fermentation (Neway, 1989). B. subtilis is a group of related strains under the family Bacillaceae. It is also called hay Bacillus because it is easily isolated from hay by enrichment culture. This bacteria is largely non pathogenic and grows quickly in inexpensive media. When cultivated in liquid medium, organisms often accumulate on the surface, giving rise to a skin or pellicle. The colonies are irregular and have a curled or hair like structure giving what is sometimes called "Medusa head" appearance. On microscopic examination tangled coils of long chains of bacilli may be found (Burrows, 1973). Priest (1989) reported the amylolytic, proteolytic and lipolytic (deesterification) activity of this organism. It has ability to secrete high levels of protein into the growth medium. Marshall (1990) reported B. subtilis as one of the few organisms that has been used to remove the bitter taste of soybeans. The lack of pathogenecity among strains of B. subtilis and any of its close relatives has resulted Food and Drug Administration granted the organism as GRAS (Generally Regarded as Safe). The genus B. subtilis is the most dominant bacterium naturally present in raw soybeans (Sarkar and Tamang, 1995). There are a number of naturally fermented soybeans foods where this species grow without adding inoculum. Some examples of these soy based foods are: Japanese HikiwariNatto, Itohiki-Natto; Thai Thua-Nao; Chinese Shui-Toushi; Nigerian Daddawa or Dawadawa; and other legume/oilseed based fermented products from different regions of Africa (Shrestha, 1997). These traditionally fermented soyfoods are littered with several other microbial species such as Enterococcus faecium, Candia parapsilosis, Geotrichum candidum etc., but Bacillus remains the sole organism carrying out the fermentation (Sarkar and Tamang, 1994). Because soybeans fermentation is still mainly based on traditional way of preparation where it is spontaneous, end products will be different depending on microbial species that are predominant during fermentation. It will also be different from one region to another and country-to-country depending on fermentation methods. However, where a single species have been used either for experimental or for standardisation purposes, production of consistent products have been obtained and this will be considered in the next sections.

\section{Methods of soybeans fermentation}

Most of the Bacillus fermented soy products are still prepared by traditional methods. So the method of preparation depends on countries/locality, family convenience, and materials available. The basic steps of product preparation such as, soaking, boiling, fermentation, incubation and finally packing remain more or less same. Figure 1 shows a typical example of B. subtilis fermented soy product, as Kinema fermentation.

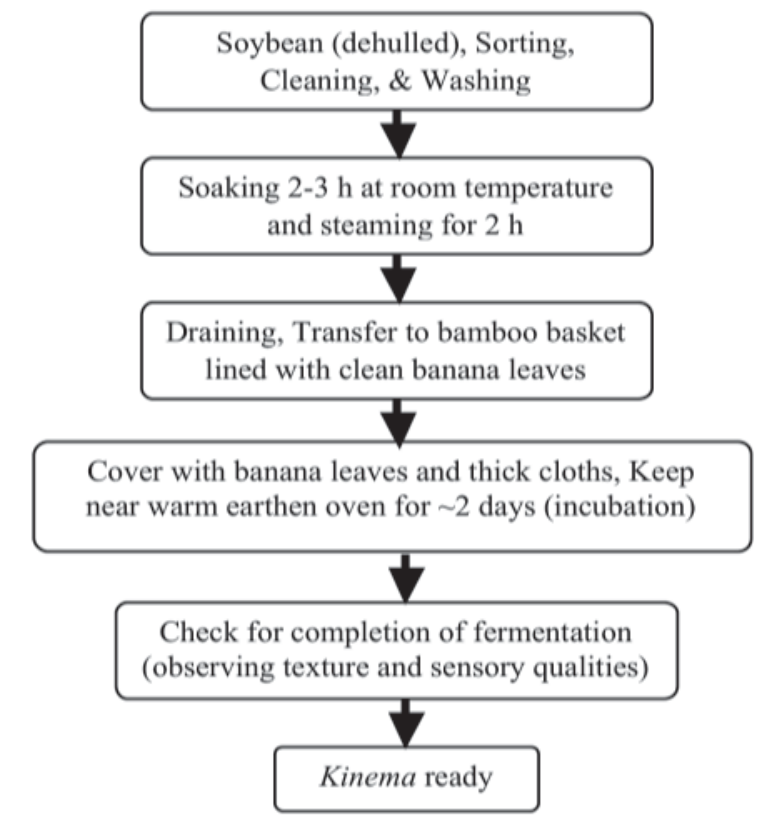

Figure 1. Flow chart of traditional fermentation of $B$. subtilis fermented soybeans (Shrestha, 1989)

Method involves wrapping soaked-boiled soybeans by banana (Musa paradisica L.) or Smith leaves (Leucosceptrum canum) or even polythene bags in bamboo lined basket which is covered with sack clothe and fermented in warm place for 2 to 3 days (Tamang and Sarkar, 1988).

Often a little bit of firewood ash is added to boiled and crushed soybeans before final fermentation commences. The fermentation method also varies, for example, in more sophisticated methods pure culture is used to inoculate the boiled soybeans. Shrestha and Noomhorm (2001) isolated $B$. subtilis from Kinema and hygienically prepared Kinema by using the pure culture. In this method soaked beans were autoclaved at $121^{\circ} \mathrm{C}$ for $35 \mathrm{~min}$, cooled to 30 to $35^{\circ} \mathrm{C}$, inoculate with pure culture, ferment at $37^{\circ} \mathrm{C}$ for 48 hours at $85 \% \mathrm{RH}$. Hu et al. (2010) and Chukeatirote et al. (2010) also prepared ThuaNao using pure culture of $B$. subtilis. Efforts have been made to increase the shelf life (2-5 days) by drying fresh product into small balls or ground these dry beans into powders (Shrestha and Athapol, 2001; Chukeatirote et al., 2010). Sarkar and colleagues have extensively studied the influence of process variables and inoculum composition on the sensory as well as product qualities (Sarkar et al., 1993; Sarkar et al., 1994; Sarkar et al., 1994; Sarkar and Tamang, 1995). Ikemnebonech, (1986) reported a number of factors such as, water activity, salt concentration, $\mathrm{pH}$ and temperature have impact on Bacillus activity in Dawadawa preparation. Uyar and Baysal (2004) reported that optimum inoculum concentration is important as low concentration of inocula does not grow fast at desirable rate and at high concentration nutrients are exhausted before enzymes are produced. 


\section{Chemical/nutritional properties of soybean and Bacillus fermented foods}

Fermentation brings substantial chemical changes in fermented soybeans (Sarkar and Tamang, 1995; Chukeatirote et al., 2010; Hu et al., 2010). The nature of fermenting organisms and preference of substrate determines the evolution of $\mathrm{pH}$ in Bacillus fermentation. Traditional $B$. subtilis fermentation showed initial decrease in $\mathrm{pH}$ from 6.94 to 6.64 (16hr) due to fermentation of carbohydrate into acids by microbial enzymes (Sarkar et al., 1993; Odunfa, 1985). Hydrolysis of protein to produce amines and ammonia through peptides and amino acids is reported to be responsible for initial change in $\mathrm{pH}$ (Odunfa, 1985). There is an increase in titratable acidity from 0.02 to $0.09 \%$ (as lactic acid) during the course of fermentation. At later stages proteolysis prevail with subsequent production of ammonia and $\mathrm{pH}$ reaches up to 8.34 at 48hr (Sarkar et al., 1993; Sarkar and Tamang, 1995). At the end of fermentation there is a slight increase in moisture level (from initial 60.5 to 64.8\%) (Sarkar and Tamang, 1995; Hu et al., 2010). Sarkar and Tamang (1995), reported that protease from $B$. subtilis degrades soy proteins resulting in significant increase in non-protein and soluble nitrogen, whereas protein nitrogen decline e.g., from $7.7 \% \mathrm{~N}$ (47.8\% protein) to $6.3 \% \mathrm{~N}$ (39.4\% protein). However, most of the literatures have reported a general increase in protein content during $B$. subtilis fermentation, e.g., 44.1 to $46.2 \%$ (traditional) and $45.1 \%$ (pure culture) fermentation on dry basis (Shrestha and Noomhorm, 2001); 35.7 to $40.3 \%$ (Hu et al., 2010); and overall $7 \%$ increase (Nikkuni et al., 1995) and 14\% increase over raw soybeans (Hayashi, 1974). It is believed that increase in protein content is associated with the increase in microbial synthesis of protein or enzymes or rearrangements of compounds followed by degradation of other compounds (Hayashi, 1974; Hu et al., 2010).

Literature data showed $B$. subtilis fermentation cause very little change in lipid content in soybeans (Shrestha and Noomhorm, 2001; Hu et al., 2010). This is despite strong lipolytic activities of microorganisms degrading a quarter of the fat content as reported by Sarkar et al. (1994). The level of titrable free fatty acid of soybeans significantly increased from 0.7 to $6 \%$ during Kinema fermentation (Shrestha and Noomhorm, 2001). In another study, Sarkar et al., (1994) reported an increase in titratable acidity from 0.01 to $0.1 \%$ (as lactic acid) and free fatty acid acidity from 0.08 to $0.3 \%$ (as linoleic acid) during Kinema preparation, suggesting release of lipase during the fermentation process. The total energy of the soybeans, however, remains unchanged during fermentation (Shrestha and Noomhorm, 2001). The effect of fermentation on ash content is inconclusive: decrease from 4.8 to $2.3 \%$ (Hu et al., (2010); remain unchanged (Shrestha and Noomhorm, 2001); and increase from 5.0 to 5.6-7.4\% (Sarkar et al., 1994). Carbohydrates are reported to decrease due to their utilisation by microbes for energy supply (Hu et al., 2010), however, chemical analysis showed no marked change (Sarkar et al., 1994; Shrestha and Noomhorm, 2001). Kinema fermentation reduces total sugar level of soybeans but increases the reducing sugar level (Shrestha and Noomhorm, 2001). Crude fiber level of soybeans also decreased during fermentation due to hydrolysis by carbohydrate splitting enzymes from B. subtilis (Shrestha and Noomhorm, 2001).

\section{Proteolytic activity of $\boldsymbol{B}$. subtilis fermented soybean}

B. subtilis has high proteolytic activity that is evident by progressive increase in trichloroacetic acid-nitrogen (TCA$\mathrm{N})$ and ammonia nitrogen with Natto fermentation, almost doubled after $48 \mathrm{~h}$ incubation. Viessanguan et al., (2005) also observed similar trend where B. subtilis during Thua Nao fermentation releases proteinases that play important role in proteolysis of soy proteins. These proteolysis reactions are reported to be responsible for the characteristic flavour of Thua Nao. It is reported three types of extra cellular enzymes namely: neutral proteases, alkaline protease and esterase play a major role during this activity and it was observed that most proteases are produced during exponential growth of microbes (Hu et al., 2010). Several proteolytic enzymes have been known to play regulatory roles in various physiological roles. Certain regulatory proteases such as fibronolytic and caseinolytic showed higher activities in Natto prepared with black soybeans (than soaked beans). These enzymes are capable of dissolving fibrin clots that can be used to cure diseased vascular system. B. Natto in soybeans fermentation is capable to produce (or enhance) â-glucosidase in soybeans may promote cleavage of â-glucosyl bond in black soybeans glucoside isoflavones to form aglycones (Hu et al., 2006; Lee and Chou, 2006). Furthermore, the fermentation of black soybeans with the starter organisms examined caused a marked increase in the content of aglycone and total anthocyanin (Kuo et al., 2006).

\section{Amino acids and fatty acid profiles}

Soybeans contain all essential amino acids but low in sulphur containing amino acids (Ang et al., 1999). B. subtilis fermentation of soybeans resulted in proteolysis of its major proteins. Sarkar et al., (1997) reported the acidic, basic and aromatic amino acids form $20.8,15.1$ and $13.0 \%$ of the total amino acid residues in Kinema. Unfermented soybeans contained only $0.2 \%$ free amino acids which increased by 60 folds in fermented product. B. subtilis fermentation also alters the amino acid profiles as there is relative increase in free acidic, hydrophobic and apolar amino acid but depletion of basic, hydrophilic and sulphur containing amino acids (Sarkar et al., 1997; Ang et al., 1999). Sarkar et al., (1997) also compared the essential amino acid (EAA) profiles of Kinema with that of the reference patterns established by $\mathrm{FAO} / \mathrm{WHO} / \mathrm{UNU}$. The result indicated the Kinema proteins are a good source of almost all EAAs and that their score is as high as that of egg and milk proteins. 
Soybeans oil contains good quality fatty acid e.g., $53 \%$ linoleic acid, $23 \%$ oleic acid, $11 \%$ palmitic acid, $8 \%$ linolenic acid, and 4\% stearic acid (Ang et al., 1999). Lipase produced during fermentation breakdown triglycerides into assimilated fatty acids (Mital and Garg, 1990). Sarkar et al., (1996) identified the linoleic acid as the major fatty acid in soybeans as well as in Kinema fermented with $B$. subtilis and other mixed cultures. Free fatty acids liberated from soybeans during fermentation play an important role in imparting typical flavour in these products. They further reported a significant increase in chain length content of fatty acid during fermentation, a phenomenon also reported by Kiuchi et al., (1976) in Natto. However, one of the negative aspects of Kinema, as reviewed by Sarkar et al., (1996), is that accumulation of free fatty acids can inhibit glycolytic and glucogenic enzymes; some hydrolyses including trypsin; and also affect fatty acid synthesis.

\section{Vitamins and mineral profiles}

Microorganisms are highly versatile and have ability to synthesize various micronutrients such as vitamins, and alter the mineral profiles (Wang, 1986). Sarkar et al., (1998) reported the preliminary steps of Kinema preparation such as soaking and cooking lower thiamine (Vitamin $\mathrm{B}_{1}$ ) and riboflavin (Vitamin $\mathrm{B}_{2}$ ) content. However, B. subtilis fermentation of cooked soybeans causes an increased concentration of thiamine (5.8 to $8.4 \mathrm{mg} / \mathrm{kg}$ ), riboflavin (6.8 to $11.6 \mathrm{mg} / \mathrm{kg}$ ) and niacin (36.4 to $4.8 \mathrm{mg} / \mathrm{kg}$ ). They further added that the presence of Enterococcus faecium in Kinema significantly reduce the level of all three vitamins. Literature is scarce on the effect of $B$. subtilis fermentation of other vitamin levels of soybeans. Tempeh (Mold) fermentation reported to reduce thiamine content almost by half but other B-vitamins level increases (Murata, 1985). Ginting and Arcot (2004) reported a significant increase in total folate content of soaked-boiled soybeans from $72 \mu \mathrm{g}$ to $416 \mu \mathrm{g}$ in fermented Tempeh. Interestingly, Kinema fermentation significantly decreases most of the minerals e.g., calcium, copper, iron, magnesium, manganese, phosphorus, potassium and zinc (Sarkar et al., 1998). It is found that the water used for soaking and cooking leach a significant amount of minerals causing a heavy loss. Despite of that Kinema still contains appreciable amount of minerals.

\section{Phenolic compounds, anthocyanins and other compounds}

Soybeans have various seed coat pigmentations, such as yellow, green, brown and black, due to presence of anthocyanin, chlorophyll and various combinations of breakdown compounds from these pigments. It has been reported that black soybeans in particularly contains numerous bioactive compounds which inhibit oxidation of low density lipoprotein oxidation (Takahashi et al., 2005), scavenge free radicals (Ignasius et al., 2009), and reduce the incidence of DNA damage by cyclophosphamide (Ribeiro and Salvadori, 2003). Most antioxidant nutrients are polyphenolic compounds acting as reducing agents, metal chelators and singlet oxygen quenchers. Many traditional fermented foods, including Natto, reported to have elevated amount of these compounds. Moktan et al., (2008) evaluated the antioxidant activities of Kinema and cooked non-fermented (CNF) soybeans by four in vitro methods: stable free radical 2,2diphenyl-1-picrylhydrazyl (DPPH) scavenging activity; $\mathrm{Fe}^{3+}$ -reducing power; $\mathrm{Fe}^{2+}$ chelating power; and activity in linoleic acid emulsion system. The total phenol content of Kinema was $144 \%$ higher than raw soybean; proven better free radical scavenger; greater reducing power; and better metal chelating power than CNF soybeans. They suggested Kinema could be exploited as a functional food to alleviate oxidative stress.

It has been observed that soaking as well as steaming reduce the polyphenol as well as anthocyanin content of soybeans (Hu et al., 2010). However, B. subtilis fermentation tends to increase total polyphenolic compound and anthocyanins, upto 10 and $250 \%$, respectively during Natto fermentation of black soybeans. Moreover, phenolic compounds increased with fermentation time due to â-glucosidase activities. In natural form, phenolic compounds are combined with sugar which reduces their availability to organism. During fermentation, this enzyme from the starter organism hydrolyses â-glucosyl bonds in soybeans that cause total increase of aglycone and anthocyanin. Hu et al., (2010) also reported DPPH radical scavenging activities of the fermented black soybeans increased linearly with fermented time and concentration.

Phytosterols are another group of compounds that is naturally present in plant foods including soybeans. It has been linked to decreased absorption of cholesterols if incorporated to human diets, therefore, regarded as one of the means of decreasing plasma cholesterol (Mattson et al., 1977). Sarkar et al., (1996) identified three phytosterols, campesterol, stigmasterol and â-sitosterol. Kinema fermentation resulted in $58 \%$ increase in overall phytosterol concentration.

\section{Isoflavones and related compounds}

Soybeans are associated with number phytochemical compounds with high biological value which tends to increase during fermentation (Wei et al., 2008). Isoflavones are class of chemical compounds related to flavonoids which act like phytoestrogen and are associated with many health benefits. In their natural form isoflavone exists as isoflavone glucose (Glucoside conjugate) which is converted into their accessible form as isoflavone aglycone under acidic or alkaline condition by $\hat{a}$-glucosidase. Setlow et al., (2004) reported that $B$. subtilis contains $\hat{a}$-glucosidase, which catalyses the hydrolysis of glucoside isoflavones to aglycone forms. Wei et al., (2008) reported that fermentation of cooked soybeans with $B$. subtilis BCRC 14718 at $37^{\circ} \mathrm{C}$ for $48 \mathrm{~h}$ effectively convert glucosides to aglycones than with other strains of $B$. subtilis, increasing the proportion of isoflavone aglycones from 12 to $68 \%$ of the total isoflavones in the fermented Natto. The proportions of the isoflavone aglycones daidzein and genistein in cooked 
soybeans fermented with B. subtilis BCRC 14718 for $48 \mathrm{~h}$ is reported to increase from 6 to $54 \%$ and from 5 to $13 \%$, respectively. Hu et al., (2010) reported the genistin and daidzin ( $\hat{a}$-glucoside) of soaked and cooked soybeans decreased as fermentation time increased whereas genistein and daidzein (aglycone) tend to increase. The proportion of isoflavone glucosides decreased significantly due to $\hat{a}$-glucosidasecatalyzed hydrolysis during with incubation with $B$. subtilis during Natto fermentation (Yin et al., 2004; Kuo et al., 2006). Likewise Chukeatirote et al., (2010) reported increase in isoflavone aglycone content in fermented soybeans and many other authors reported its increase in fermented soybean (Wei et al., 2008).

\section{Aromatic compounds and flavouring agents}

Microbial fermented soybeans, particularly B. subtilis, have a distinct flavour. The microbial activity during fermentation of soybeans which is linked to extra cellular hydrolase enzymes including amylase, proteases, lipases and sucrose is mostly responsible for the change in volatile compounds, contributing the typical flavour. Leejeerajumnean et al., (2001) reported a significant increase in concentration of volatile compounds, up to 100times in concentration, during fermentation of cooked soybeans within 72 hours. The major components of these volatiles are 3-hydroxybutanone (acetoin), 2-methylbutanoic acid, pyrazines, and dimethyl sulfides together with other aromatic compounds. Similarly, Owens et al., (1997) reported that under anaerobic condition B. subtilis secretes á-acetolate which is decarboxylated by á-acetolate decarboxylase (extra cellular enzyme) to acetoine. Acetoine is then oxidised to diacetyl which is an aromatic compound linked in to flavour of many foods, such as yogurt. Production of ketone compounds is due to degradation of soy lipids and amino acids (Owens et al., 1997). Owens et al., (1997) listed changes in a number of aliphatic compounds; aliphatic aldehydes; aliphatic ketones; aliphatic acids and esters; pyrazines; furans; sulphur compounds; aromatic compounds; and other miscellaneous compounds during the B. subtilis fermentation. In particular, concentration of pyrazines compounds increase well above their initial level which contributing significantly to the aroma of fermented soybeans. However, drying of Thua-Nao drastically lower the concentration of volatile compounds in commercial $\mathrm{NaO}$ (fermented soybeans), reducing level of aliphatic acids, esters and sulphur compounds, but enhancing hexanol and trimetylpyrazine level. The loss of volatile compounds can be minimized by improving drying method or by alternative of preservation method (Owens et al., 1997).

\section{Physico-chemical properties}

Fermentation reduces firmness of cooked soybean and increases viscosity of the food matrix due to formation of mucilaginous materials. Firmness of $B$. Natto black fermented soy bean reduced gradually decrease from $45.6 \mathrm{~kg}$ (force) in steamed bean with incubation time, $36.7 \mathrm{~kg}$ after $48 \mathrm{~h}$ fermentation (Hu et al., 2010). Viscosity measurement of Natto extract showed the viscosity of the cooked soybeans increased with increasing incubation time. Shrestha and Noomhorm, (2002) dried the Kinema, prepared by traditional as well as pure culture method, in hot air oven, ground into fine powder and anlaysed for their physico-chemical properties (Table 1).

\begin{tabular}{|c|c|c|c|}
\hline Properties $^{2}$ & $\begin{array}{c}\text { Raw } \\
\text { oybeans }\end{array}$ & $\begin{array}{c}\text { Kinema } \\
\text { (traditional) }\end{array}$ & $\begin{array}{c}\text { Kinema } \\
\text { (pure culture) }\end{array}$ \\
\hline Moisture, $\%$ & 6.6 & 7.2 & 6.8 \\
\hline Protein, \% & 44.0 & 46.2 & 45.1 \\
\hline Lipid, \% & 21.8 & 22.2 & 23.0 \\
\hline Ash, $\%$ & 4.7 & 4.8 & 4.5 \\
\hline Total carbohydrate, $\%$ & 29.8 & 26.3 & 27.4 \\
\hline Crude fiber, $\%$ & 6.5 & 4.2 & 4.8 \\
\hline Total sugar, $\%$ & 21.0 & 14.5 & 16.5 \\
\hline Reducing sugar $\%$ & 3.1 & 5.1 & 4.7 \\
\hline Energy, MJ/100g & 1.9 & 1.9 & 1.9 \\
\hline Free fatty acid, $\%$ & 0.7 & 3.1 & 6.2 \\
\hline Bulk density, $\mathrm{g} / \mathrm{mL}$ & 0.6 & 0.8 & 0.7 \\
\hline Water binding capacity, $\mathrm{g} / \mathrm{g}$ & 3.5 & 3.5 & 2.5 \\
\hline Oil binding capacity, $\mathrm{g} / \mathrm{g}$ & 2.4 & 1.9 & 1.9 \\
\hline Wettability, min & 0.4 & 0.4 & 1.1 \\
\hline Emulsifying activity index, $\mathrm{m}^{2} / \mathrm{g}$ & 4.7 & 5.7 & 8.5 \\
\hline Nitrogen solubility index, $\%$ & 17.1 & 29.2 & 66.0 \\
\hline $\mathrm{PH}$ & 6.93 & 6.9 & 6.5 \\
\hline Foam volume increase, $\%$ & 8.1 & 22.00 & 6.1 \\
\hline LGC*, \%w/v & 22 & 20 & NG \\
\hline $\mathrm{L}^{\psi}$ & 84.2 & 76.7 & 58.7 \\
\hline$a^{\psi}$ & 0.54 & 2.32 & 13.3 \\
\hline$b^{\psi}$ & 26.5 & 27.44 & 35.9 \\
\hline Hue & 88.84 & 86.16 & 69.66 \\
\hline
\end{tabular}

They reported bulk density of the Kinema powders is only slight higher than soyflour. Formation of gummy materials on the surface of the beans due to Bacillus fermentation could have contributed greater inter-particle adhesion in Kinema flour and hence the density. The wettability of Kinema prepared by pure culture method was much higher than soyflour, most likely to be contributed by autoclaving as it can affect the surface activity and porosity of particles, causing higher wettability.

The emulsifying activity indices showed Kinema powder has higher values compared to soyflour. Nitrogen solubility index of protein powders is much higher than soyflour which is also linked to emulsifying capacity of the soy protein (Liu, 1999). Higher protein solubility of Kinema powder should be helpful in incorporation of this nutritious product into other food formulations. The nitrogen solubility index of Kinema flours is higher than soyflours. B. subtilis is known to produce a number of proteolytic enzymes which hydrolyze protein to smaller peptides and finally ammonia (Priest, 1989). These chemicals are responsible for increase in water-soluble nitrogen and flavour of Kinema (Sarkar et al., 1994; Nikkuni et al., 1995).

Data on the foaming capacity shows Bacillus fermentation did not affect foaming capacity of soyflour. Yatsumatsu et 
al., (1972) reported the denaturation of protein during processing and also the lipid materials in soy preparations are very detrimental to foaming because they destabilized protein films. The stability of foam resulting from soyflour and Kinema powder was almost same, total collapse occurred within $2 \mathrm{hr}$ (Shrestha and Noomhorm, 2001). Water retention capacity is an index of the amount of water retained within a protein matrix or other system under certain conditions. Water retention by the Kinema flours is lower than that by soyflours which might have been caused by physical and chemical modifications of the protein structure caused by heating and fermentation. However, there was no marked difference in oil binding capacity of these three flours. Kinema flours were significantly darker, more reddish ('a') and more yellowish ('b') than soyflours. The dark and brown colours of Kinema flours, particularly PKF, were probably due to a greater degree of heat treatment during processing, resulting in a Maillard type browning reaction.

\section{Health benefits of $B$. subtilis fermented soybeans}

Fermentation of soybeans, particularly with B. subtilis, lead to extensive hydrolysis of all the macromolecules such as proteins to smaller peptides, amino acids and simple sulphur and nitrogen compounds; starch into oligosaccharides and simple sugars and lipids into simple fatty acids. One of the key health benefits of $B$. subtilis fermentation is improved digestibility of normally indigestible soybeans (and its components). It reported to improve the quantity of highly digestible soluble matters by almost three times ( 22 to $65 \%$ ) and at the same time almost $40 \%$ total defatted dry matter becomes dialyzable due to degradation of high molecular weight compounds (Kiers et al., 2000). One of the most reported health benefits of $B$. subtilis fermentation is almost complete removal of indigestible oligosaccharides such as sucrose, trisaccharides (raffinose), tetrasaccharides (stachyose) which are responsible for indigestion and flatulence in humans and in monogastric animals (Sarkar and Tamang, 1995; Esteves et al., 2010). Fermentation reduces anti-nutrients level in soybeans which hinder the availability of proteins and phytochemicals. It does help in improving the protein digestibility (Esteves et al., 2010). Shrestha and Noomhorm, (2001), found the urease activity of Kinema (dried) is close to zero and concluded that steps Kinema preparation lead to inactivation of anti-nutrients such as trypsin inhibitors and other biologically active enzymes in naturally present in raw soybeans.

In developing countries enteric diseases caused by strains of Enterotoxigenic E. coli (ETEC) are common type of colibacillosis (cause several diarrhoea) in pigs, calves as well as in human beings (Nagy and Fekete, 1999). It has been realized that antibiotics and anti-microbial compounds given to starter piglet diets for their health and growth-promoting properties, but the continued use of sub-therapeutic levels of antibiotics in animal feeds may contribute to antibiotic resistance in humans. Kyriakis et al., (1999) suggested that probiotics from strains of lactic acid bacteria and Bacillus spp. could be used as alternative feed additives to piglets so as to replace antibiotics and antimicrobial compounds in their feeds. Kalavi et al., (1996) claimed Rhizopus fermented soybeans (Tempeh) reduces the duration of diarrhoea when added to the diet of malnourished children. Kiers et al., (2003) showed that while fermented soybeans inhibits adhesion of ETEC K88 in Rhizopus fermented soybeans, Bacillus acting as probiotics allow Bacillus fermented products to inhibit proliferation of pathogens in gut. Furthermore, piglets fed with $B$. subtilis fermented soybeans showed increased feed intake by $12 \%$, average daily weight gain by $21 \%$ and feed efficiency by $8 \%$. They further confirmed that fermented soybeans could be used as source of food for weaned pig to reduce their death rate and use of antibiotics and promote growth for either pigs or under nourished people.

It is already mentioned that B. subtilis fermented soybeans are richer in isoflavin aglycone and phenolic compounds. Wei et al., (2008) reported that isoflavone by acting like oestrogen is able to reduce risks related to cardiovascular diseases, lower rate of prostate, breast and colon cancers and improve health benefits. Increase of total phenol and aglycone isoflavone enhances the ability of DPPH (2,2diphenyl -1 picrylhydrazyl) which acts as antioxidant due to its scavenging ability of free radicals by hindering oxidation of low density lipoprotein, reduces DNA damage by cyclophosphamide and potentially carcinogenic compounds (Omoni and Aluko, 2005; Hue et al., 2010). Similarly, Kon et al., (2010) linked consumption of fermented soybeans with reduction of diabetes type- 2 where improve of glucose control and insulin resistance were observed. They emphasised that occurrence of cardiovascular diseases and other organic diseases are rare in Asian countries where consumption of fermented soybeans is consumed at rate of 9 to $30 \mathrm{~g}$ per day compared to western countries where consumption of fermented soybeans is rare. They further attributed this ability not only to isoflavone, but also to some other peptides that might be produced during fermentation which are still understudy (Kon et al., 2010).

\section{Methods to improve quality of $B$. subtilis fermented foods}

The products like Kinema, Thua-Nao and Dawadwa are still prepared in primitive way as it was done centuries ago. There is a great health risk in eating these products as it is largely prepared in unhygienic way (Shrestha, 1997). There is now an increased scientific knowledge on different products of fermented soybeans in order to improve their quality, standardisation and its availability throughout the year. It mainly consists of identification and isolation of microorganisms which pre-dominate the fermented product and used as a specific inoculum for fermentation. There have been several studies where pure B. subtilis (Natto) (isolated or from stock culture) was used as a primary inoculum to produce hygienic, safe and better quality fermented soy products (Shrestha, 1997; Hu et al., 2000; Chukeatitrot et al., 
2010). Commercial production of Natto in Japan is very common. In Nigerian, B. subtilis inoculated soybeans (Dawadawa) is fermented in shorter incubation time than traditional ones, with consistent quality, properly packaged and marketed (Iwuoha and Eke, 1996). Natto production using B. Natto at fermentation time of $18 \mathrm{hr}$, as compared to $48 \mathrm{~h}$ in traditional method, reported to give equally good quality product (Hu et al., 2010). However, fermented products are still largely produced by traditional method, therefore, it was suggested to establish control measures and follow good manufacturing practice (GMP) for people involved in its production and commercialisation to ensure its safety (Iwuoha and Eke, 1996).

Fermented soy based foods such as Natto, Kinema, ThuaNoa, Dawadawa and many other similar foods are very good source of high quality protein source to the poor masses of developing countries who cannot afford the expensive source of proteins such as meat, fish, egg and milk. However, all these B. subtilis fermented soy products possess characteristic odour, slimy appearance and low shelf-life and which make it not so popular among the larger population. In order to increase usefulness and acceptability, diversification of the products has long been realized. Shrestha (1997) reported drying of Kinema removes its slimy texture and also reduces its 'rotten bean' flavour. Besides, dried Kinema had much higher shelf-life than naturally fermented soybeans. High protein biscuits, crackers and soup mix have been produced by incorporating Kinema and Natto flour (Watanabe, 1969; Shrestha, 1997). Kinema fortified biscuits had about $17 \%$ proteins and also well liked by majority of sensory panellists (Shrestha, 1997).

\section{Conclusion}

Soybeans is one of the richest source of major macronutrients, particularly proteins and fats, and micronutrients such as vitamins, minerals, phytosterols, polyphenols etc. Over the years, a number of foods based on soybeans have been developed, fermented soybeans food are some of them. Among them, B. subtilis fermented soy foods such as, Kinenma, Natto, Thua-Nao, Dawadawa etc., are traditionally prepared in many cultures around Asian and Africa. This unique product has typical mucilaginous appearance, putrid and ammoniacal dour and rich in macro as well as micronutrients and bioactive compounds. B. subtilis fermentation results in proteolysis of soy polypeptides, altering its digestibility, taste and flavor as well as improving the protein quality. Besides it inactivates anti-nutritional factors, improve digestibility, remove indigestible oligosaccharides, increase isoflavone, proteolytic enzymes, phytosterols that can make difference in human health. The quality of traditionally fermented foods however is low that warrants the use of pure culture to improve the quality as well as safety of these foods. The nutritive qualities of $B$. subtilis fermented soybeans can best be utilized by developing it into new products.

\section{References}

Ang C. Y. W., Liu K. and Huang Y. (1999). Asian foods Science and Technology. Technomic publishing company Inc., pp. 139-195.

Beuchat L. R. (1984). Fermented soybeans foods. Food Technol., June issue, 64-70.

Burrows W. (1973). Textbook of Microbiology. W. B. Saunders Company.pp. 607-617.

Chukeatitrote E., Dajanta K. and Apichartssrangkoa A. (2010) Thua Nao indigenous Thai fermented soybeans. J. of Biol. Sci., 10 (6): 581-583

Esteves E. A., Martino H. S. D., Olivieira F. C. E., Bressan J. and Costa N. M. B. (2010). Chemical composition of soybeans cultivar lacking lipoxygenases, Food Chem., 122: $238-242$.

Ginting E. and Arcot J. (2004). High-performance liquid chromatographic determination of naturally occurring folates during Tempeh preparation. J. of Agri. and Food Chem., 52: 7752-7758.

Hayashi U. (1974). Study of the cause of increase in nitrogen content in the course of manufacture of Natto. IV. Experiment to confirm the ability of Bacillus Natto to utilize atmospheric nitrogen by means of stable isotopes ${ }^{15} \mathrm{~N}$. Reports of Teikoku Joshi Daigaku Laboratory of Natto. 49: 30-34.

Hu Y., Ge C., Yuan W., Zhu R., Zhang W., Due L. and Xue J. (2010). Characterization of fermented black soybeans Natto inoculated with Bacillus Natto during fermentation. J. of Sci. Food and Agri., 90: 1194-1202.

Ignasius R. A., Mary A. Umar S. and Prihati S. N. (2009). In vitro antioxidant activity of anthocyanins of black soybeans seed coat in human low-density lipoprotein (LDL). Food Chem., 112: 659-663.

Ikemnebonech M. J., Kok R. and Ingram J. M. (1986). Processing and fermentation of the African locust bean (parkia-filicoidea welw) to produce dawadawa. J. of the Sci. of Food and Agri., 37 (3): 273-282.

Iwuoha C. I. and Eke O. S. (1996). Nigerian indigenous fermented foods, their traditional process operation, inherent problems, improvements and current status. Food Research Inter., 29 (5-6): 527-540.

Kalavi F. N. M., Muroki N. M., Omwega A. M. and Mwadime R. K. N. (1996). Effect of Tempeh yellow maize porridge and milk yellow maize porridge on growth rate, diarrhoea and duration of rehabilitation of malnourished children. East African Medical J., 73: 427-431.

Kiers J. L., Meijer J. C., Nout M. J. R., Rombouts F. M., Naburs M. J.A. and Van der Meulen J. (2003). Effect of fermented 
soybeans on diarrhoea and feed efficiency in weaned Piglets. J. of Applied Microbiol., 95: 545-552

Kiers J. L., Van Laeken A. E. A., Rambouts F. M. and Nout M. J. R. (2000). In vitro digestibility Of Bacillus fermented soybeans, Inter. J. of Food Microbiol., 60: 163-169.

Kiuchi K., Ohta O., Itoh H., Takahayahsi T. and Ebine H. (1976). Studies on lipids of Natto. Journal of Agricultural and Food Chem., 55: 271-272.

Kon D. Y., Daily J. W., Kim H. J. and Park S. (2010). Antidiabetic effects of fermented soy Soybeans products on type 2 diabetes. Nutrition Res., 30 (1): 1-13.

Kuo L. C., Cheng W. Y., Wu R. Y., Huang C. J. and Lee K. T. (2006). Hydrolysis of black soybeans isoflavone glycosides by Bacillus subtilis Natto. Appl. Microbiol. Biotech., 73: 314-320.

Kyriakis S. C., Tsiloyiannis V. K., Vlemmas J., Sarris K., Tsinas A. C., Alexopoulos C. and Jansegers L. (1999). The effect of probiotic LSP 122 on the control of postweaning diarrhoea syndrome of piglets. Res. in Veterinary Sci., 67: 223-228.

Lee I. H. and Chou C. C. (2006). Distribution profiles of isoflavone isomers in black bean kois prepared with various filamentous fungi. J. of Agri. and Food Chem., 54: 1309-1314.

Leejeerajumnean A., Duckham S. C., Owens J. D. and Ames J. M. (2001). Volatile compounds in Bacillus fermented soybeans. J. of the Sci. of Agri., 81: 525-529

Marshall W. E. (1990). Bitterness in Soy and Methods for its Removal. In: Bitterness in Food and Beverages. Rouseff R. L. (Ed), Development in Food Science - 25, Elsevier.

Mattson F. H., Volpenhein R. A., Erickson B. A. (1977). Effect of plant sterol esters on the adsorption of dietary cholesterol. J. of Nutri., 107: 1139-1146.

Mital B. K. and Garg S. K. (1990). Tempeh-technology and food value. Food Review International, 6: 213-224.

Moktan B., Saha J., and Sarkar P. K. (2008). Antioxidant activities of soybeans as affected by Bacillusfermentation to Kinema. Food Research International, 41(6): 586-593.

Murata K. (1985). Formation of Antioxidants and Nutrients in Tempeh. In: Proceedings from Asian Symposium on NonSalted Soybeans Fermentation, National Food Research Institute, Tsukuba Science City, Japan. pp. 186-198.

Nagy B. and Fekete P. Z. (1999). Enterotoxigenic Escherichia coli (ETEC) in farm animals. Veterinary Research, 30: 259-284.

Neway O. (1989). Fermentation Process Development of Industrial Organisms. Marcel Dekker, Madison Avenue, New York. pp. 73-75.
Nikkuni S., Karki T. B., Vilkhu K. S., Suzuki T. S., Shindon K., Suzuki. C., Noriyuki O. (1995). Mineral and amino acid content of Kinema, a fermented soybeans food prepared in Nepal. Food Sci. Tech. Inter., 1: 107-111.

Odunfa S. A. (1985). Biochemical changes in fermenting African Locus bean (Parkia biglobasa) during riu fermentation. J. of Food Tech., 20: 295-303.

Omoni A. O. and Aluko R. E. (2005). Soybeans foods and their benefits: Potential mechanisms of action. Nutrition Reviews, 63(8): 272-283.

Owens J. D., Allargheny N., Kipping G. and Ames J. M. (1997). Formation of volatile compounds during Bacillus subtilis fermentation of soybeans. J. the Sci. of Agri., 74: $132-140$

Priest F. G. (1989). Isolation and Identification of Aerobic Endospore Forming Bacteria. In: Bacillus. Harwood, C. R. (Ed). Plenum Press, London. Pp. 38-46.

Ribeiro L. R. and Salvadori D. M. F. (2003). Black bean (Phaseolus vulgarus L.) as a protective agent against DNA damage in mice. Food Chemical Toxicology, 41: 1671-1676.

Sarkar P. K. and Tamang J. P. (1994). The influence of process variables and inoculum composition on the sensory quality of Kinema. Food Microbiol., 11(4): 317-325.

Sarkar P. K. and Tamang J. P. (1995). Changes in the microbial profile and proximate composition during natural and controlled fermentations of soybeans to produce Kinema. Food Microbiol., 12 (4): 317-325.

Sarkar P. K., Cook P. E. and Owens J. D. (1993). Bacillusfermentation of soybeans. World J. of Microbiol. and Biotechnol., 9 (3): 295-299.

Sarkar P. K., Jones L. J., Craven G. S. and Somerset S. M. (1997). Oligosaccharide profiles of soybeans during Kinema production. Letters in Applied Microbiology, 24(5): 337-339.

Sarkar P. K., Jones L. J., Gore W., Craven G. S. and Somerset S. M. (1996). Changes in soya bean lipid profiles during Kinema production. J. of the Sci. of Food and Agri., 71 (3): 321-328.

Sarkar P. K., Morrison E., Tinggi U., Somerset S. M. and Craven G. S. (1998). B-group vitamin and mineral contents of soybeans during Kinema production. J. of the Sci. of Food and Agri., 78 (4): 498-502.

Sarkar P. K., Tamang J. P., Cook P. E. and Owens J. D. (1994). Kinema - a traditional soybeans fermented foodproximate composition and microflora. Food Microbiol., 11(1): 47-55. 
Setlow B., Cabrera-Martinez R. M. and Setlow P. (2004). Mechanism of the hydrolysis of 4-methylumbelliferylbeta-D-glucoside by germinating and outgrowing spores of Bacillus species. J. of Applied Microbiol., 96 (6): 1245-1255.

Shrestha A. K. (1989). Comparative study on the Preparation and Quality Evaluation of Natto and Kinema. B. Tech dissertation. Central Campus of Technology, Tribhuvan University, Dharan, Nepal.

Shrestha A. K. (1997). Preparation, evaluation and utilization of Kinema (solid state fermented soyfood from Nepal) flour. M.Sc. Thesis. Asian Institute of Technology, Thailand, Bangkok.

Shrestha A. K. and Noomhorm A. (2001). Composition and functional properties of fermented soybeans flour (Kinema). J. of Food Sci. and Tech., Mysore, 38(5): 467470.

Shrestha A. K. and Noomhorm A. (2002). Comparison of physico-chemical properties of biscuits supplemented with soy and Kinema flours. Intr. J. of Food Sci. and Technol., 37(4): 361-368.

Takahashi R., Ohmori R,, Kiyose C., Momiyama, Y., Ohsuzu, F. and Kondo, K. (2005). Antioxidant activities of black and yellow soybeans against low density lipoprotein oxidation. J. of Agri. and Food Chem., 53: 4578-4582.

Tamang J. P. and Sarkar P. B. (1988). Traditional fermented foods and beverages of Darjeeling and Sikkim-a review. J. of Sci. Food and Agri., 44: 375-385.
Uyar F. and Baysal Z. (2004). Production and optimization of process parameters for alkaline protease production by newly isolated Bacillus sp. under solid state fermentation. Process Biochem., 39: 1893-1898.

Visessanguan W., Benjakul S., Potachareon W., Panya A., and Riebroy S. (2005). Accelerated proteolysis of soy proteins during fermentation of Thua-Nao inoculated with Bacillus subtilis. J. of Food Biochem., 29(4): 349366.

Wang H. L. (1986). Nutritional quality of fermented foods. In: Indigenous Fermented Food of Non-Western Origin (Mycologia Memoir No. 11). Hesseltine C. S. and Wang H. L., (Eds.). Berlin, Germany. pp. 289-301.

Watanabe T. (1969). Industrial Production of Soybeans Food in Japan. In: UNIDO Expert Group Meeting on Soybeans Processing and Use. USDA, Pretoria, Nov 17-21.

Wei Q. K., Chen T. R. and Chen J. T. (2008). Use of Bacillus subtilis to enrich isoflavone glycones in fermented Natto', J. of the Sci. of Food and Agri., 88: 1007-1011.

Yatsomatsu K., Toda J., Wada M., Misaki S., Monaka S. and Ishii, Y. (1972). Whipping and emulsifying properties of soybeans products. Agri. and Biological Chem., 36: 719727.

Yin L. J., Li L. T., Li H., Saito M. and Eizo T. (2005). Effects of fermentation on the content and composition of isoflavones and $\hat{a}$-glucosidase activity in $S u f u$, Bioscience Biotech. and Biochem., 69: 267-272.

Yoshida S. (1988). Natto an Acquired Taste. Pacific Friend, Japanase Monthly Magazine, October-1988. 